Postgrad. MED. J. (1965), 41, 139

\title{
SPLENIC CYSTS
}

\author{
N. IsLAM, B.Sc., M.B., B.S., M.R.C.P.E.
}

Department of Pathology, Dudley Road Hospital, Birmingham.

SPLENIC CYSTS are rare. Pemberton (quoted by Fowler, 1940) reported four examples among 800 splenectomies at the Mayo Clinic during a thirty year period. Fowler (1953) reviewed a total of 265 cysts from the available world literature. Less than one hundred such cases have been reported since then (Schecter, Owens and Palmieri, 1962), and little reference has been made to the condition in this country. Sixty-one splenectomies were performed in this hospital during 1941-1958, but no splenic cysts were encountered. During the period 1959 to 1963, however, there have been four examples in sixty-one splenectomies.

\section{Case Reports}

\section{Case No. 1}

A girl of 11 was admitted in January 1959 for investigation of a palpable mass in the left abdomen. She had been complaining of discomfort and heaviness in the abdomen for a few weeks, and of scanty bleeding per vagina with occasional dull pain in the lower abdomen for one week. This was thought to be her. first period.

The mass was palpable on the left side extending to the umbilicus; it was firm and slightly tender. Urinalysis, blood studies, sternal marrow biopsy and liver function tests were within normal limits. Straight X-ray of the abdomen suggested a large spleen pressing on adjacent viscera. Percutaneous splenic venography failed to outline the portal venous system and the dye was diffusely diluted into a "big splenic cyst".

At laparotomy an enormous spleen measuring $11 \times 6 \times 5 \mathrm{~cm}$. was removed. At the upper pole there was a unilocular cyst measuring $8 \mathrm{~cm}$. in its greatest diameter, containing brown, turbid fluid. The wall was $2 \mathrm{~cm}$. thick and the inner surface was covered by fibrinous material, connected by fibrous bands. Microscopically, the inner wall was lined by endothelium, and in areas was covered by fibrin. Many blood-filled spaces, also lined by endothelium, were seen deep in the wall, suggesting that the cyst was angiomatous (Fig. 1).

The patient made an uneventful recovery after operation and the periods are now normal.

\section{Case No. 2}

A young girl, aged 16, was found to have an enlarged mass in the left hypochondrium at a routine medical examination in September, 1961. On direct questioning she admitted to a heavy feeling in the left upper abdomen for about four months. There was no history of injury and no other complaint. Periods were irregular with scanty discharge. Hæmatological, biochemical and urine investigations were all within normal limits.

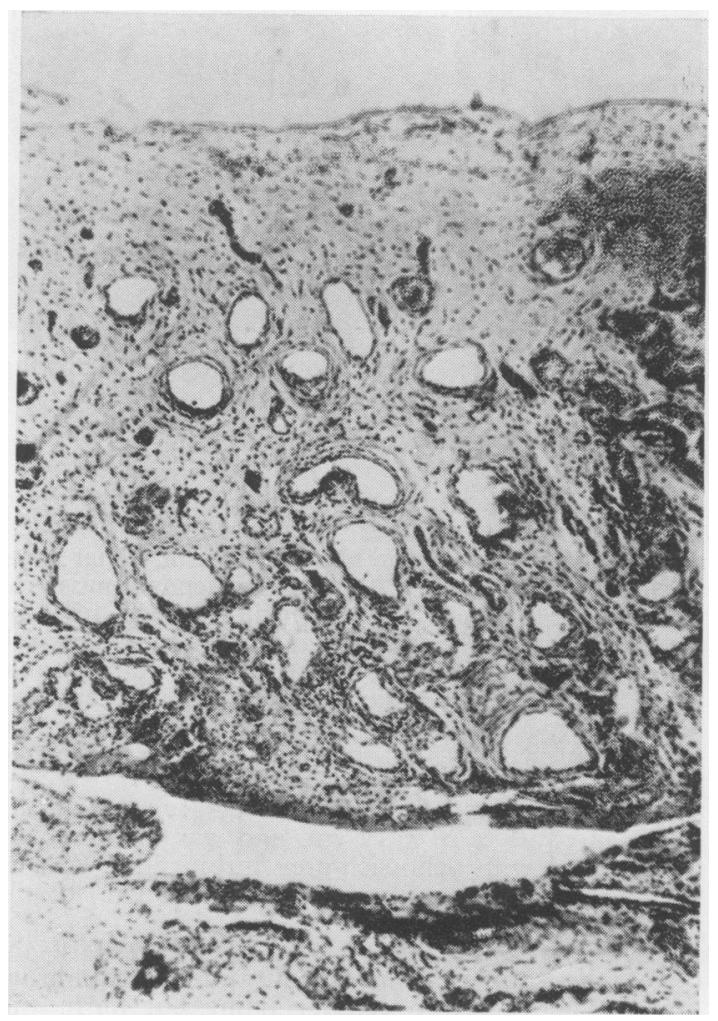

FIG. 1.-CASE 1: Low power photomicrograph showing splenic cyst lined by endothelium. Many blood-filled spaces, also lined by endothelium, are seen deep in the wall of the cyst.

Intravenous pyelography showed a normal right kidney, but the left kidney was not visualised (Fig. 2). A large mass occupied the whole of the left upper abdomen. Retrograde pyelogram showed the left kidney displaced posteriorly with some slight hydronephrosis. A barium meal revealed that the stomach was displaced to the right.

At laparotomy a very large cystic tumour of the spleen, extending to the left iliac fossa, was removed. This measured $30 \times 23 \times 18 \mathrm{~cm}$. and was filled with brown, turbid fluid. The inner wall showed fibrous trabeculæ. A crescentic rim of normal splenic tissue was present ( $3 \times 5 \times 3 \mathrm{~cm}$.) at the upper pole (Fig. 3). The kidneys appeared normal.

Histologically the wall of the cyst showed wellformed fibrous tissue with fibrin attached in places. No true cell lining was found. Scattered pseudoxanthomatous cells were present, some of which contained pigment. It seemed clear that at some time there had been extensive bleeding into the cyst.

The post-operative course was uneventful and a further pyelogram showed normally functioning kidneys. 


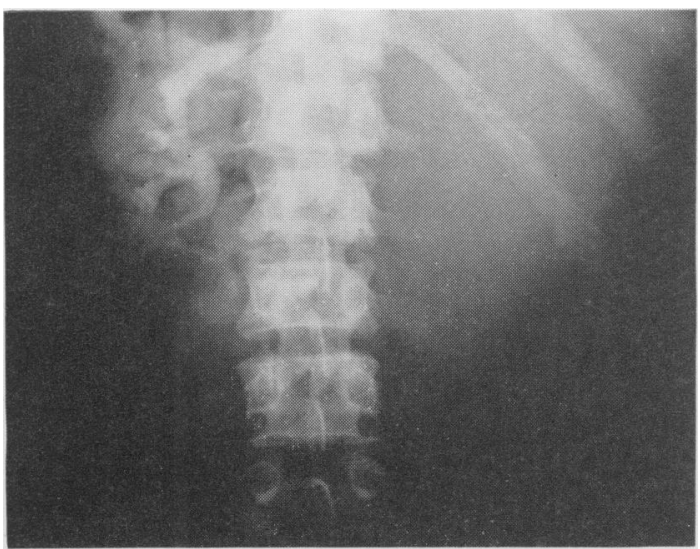

FIG. 2.-CASE 2: Intravenous pylogram showing non-functioning left kidney.

\section{Case No. 3}

A 23-year-old male was admitted in September, 1962 complaining of pain and swelling in the left side of the abdomen for about a month. There was no history of trauma. A huge non-tender mass was palpated in the left hypochondrium which had the features of an enlarged spleen. A well marked rub was heard over it. All investigations were normal apart from an I.V.P. which showed a non-functioning left kidney. A retrograde pyelogram revealed that the kidney was present but had been displaced to the right by a large tumour mass.

At laparotomy a huge splenic cyst was removed. It measured $25 \times 20 \times 12 \mathrm{~cm}$. and was multilocular; it was filled with yellowish-grey turbid fluid. Splenic tissue occupied a small area $(3 \times 3 \times 2 \mathrm{~cm}$.) at the lower pole.

Microscopic examination showed the wall of the cyst to be composed mainly of well-formed fibrous tissue. There was no cellular lining but fibrin was found attached in a scattered fashion.

Recovery was uneventful, and a post-operative intravenous pyelogram showed that both kidneys were functioning normally.

\section{Case No. 4}

A 14-year-old boy was admitted in 1962 with a swelling in the abdomen which had been increasing in size, although it was not causing him any discomfort. He had had an attack of jaundice 2 years previously, lasting a week and preceded by anorexia. Eighteen months before admission he had had a bicycle accident and had fallen on his left side.

Physical examination revealed a markedly enlarged spleen. The liver was not palpated. Hæmatological and biochemical investigations were normal except for a depressed platelet count $(75,000 / \mu \mathrm{mm}$.). Barium meal showed gross displacement of the stomach to the right by the enlarged spleen. Splenic venography failed to visualise the portal venous system but the injected dye diffused into a large cyst (Fig. 4).

At laparotomy a large splenic cyst ( $23 \times 20 \times 15$ $\mathrm{cm}$.) was removed. It had a dual blood supply, there being separate branches from the main splenic artery. At the lower pole there was a wedge of normal splenic tissue measuring $6 \times 5 \times 3 \mathrm{~cm}$., and a rim of splenic tissue $1.5 \mathrm{~cm}$. in thickness lined the rest

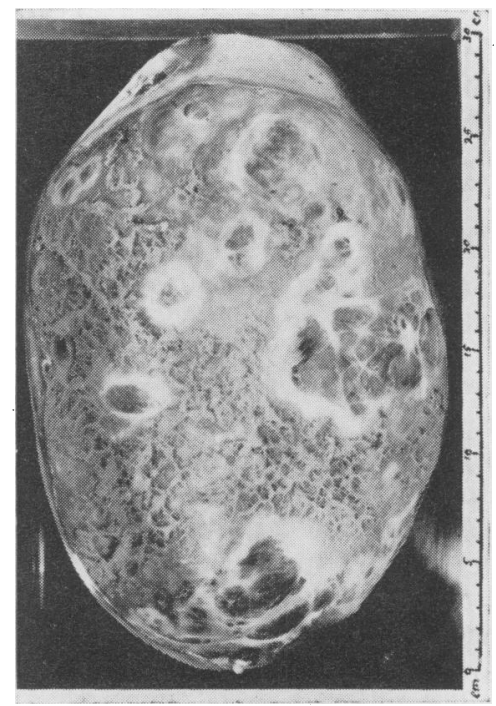

FIG. 3.-CASE 2: Splenic cyst-the upper pole show a rim of normal splenic tissue.

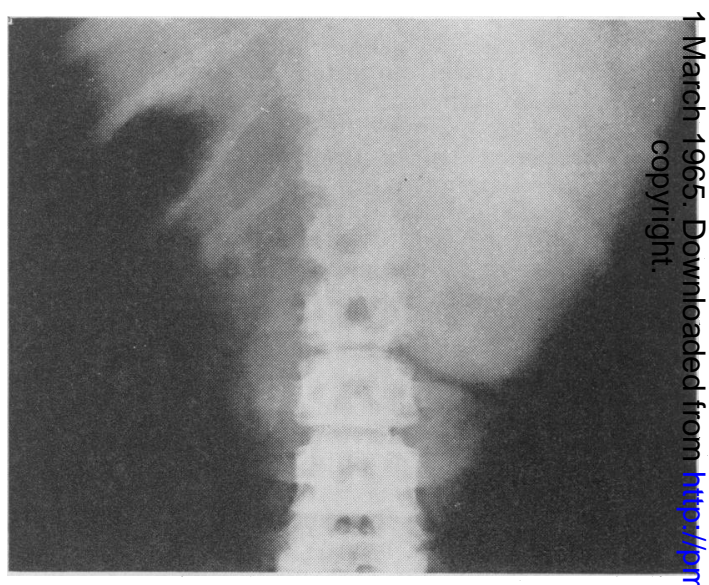

Fig. 4.-CASE 4: Percutaneous splenic venogrạm showing outline of splenic cyst.

of the tumour. The cyst was unilocular and filled with brown turbid fluid. Microscopically the cyst was lined by stratified squamous epithelium (Fig. 5), while fibrous tissue and normal splenic tissue were present in the deeper parts.

The patient made an uneventful recovery.

\section{Discussion}

There are many causes of splenomegaly an most are commoner than splenic cyst. For this reason, and also because of the absence of anty specific clinical picture, diagnosis is frequentfy difficult. $75 \%$ of splenic cysts occur betweeg the ages of ten and fifty, and $60 \%$ are found in females in the child-bearing period, probabby due to the influences of menstruation ang 


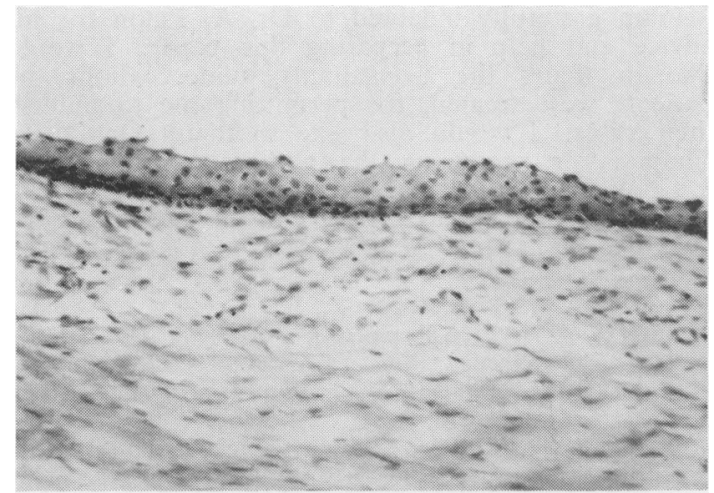

Fig. 5.-CASE 4: High power photomicrograph showing the inner wall of the cyst lined by squamous epithelium.

pregnancy. Indeed there appears to be some relationship with the menstrual cycle, since irregularity of menstruation has been remarked on by other authors and was present in both female patients in the present group.

Symptoms may be absent or slight even when the cyst is very large (Case 2). On the other hand pressure on neighbouring structures may cause symptoms suggesting disease in the chest, abdomen, pelvis or even in the lower limbs (Fowler, 1953). Pain or discomfort in the left hypochondrium is usual, and the swelling may be noticed by the patient. Vomiting and fever may occur but constitutional symptoms are usually absent.

Hæmatological and biochemical investigations are essential preliminaries to diagnosis and are nearly always normal. Radiological examination may be confusing unless it is realised that displacement of the left kidney may lead to failure of visualisation on intravenous pyelography (Case 2 and 3). Why this should be so is not known, since post-operative IVPs are normal. Percutaneous splenic venography appears to be a valuable and safe means of confirming the diagnosis (Case 1 and 4). A correct preoperative diagnosis was made in all four patients in the present series.

\section{Classification}

This has always been unsatisfactory. Attempts have been made to classify splenic cysts according to the presence or absence of cell lining, the types of cell lining and the character of the fluid present. The comprehensive classifications put forward by Fowler (1940) and by McClure and Attemeier (1942) appear too complicated. On the other hand the classification suggested by Smith and Gowing (1953) is unconvincing.

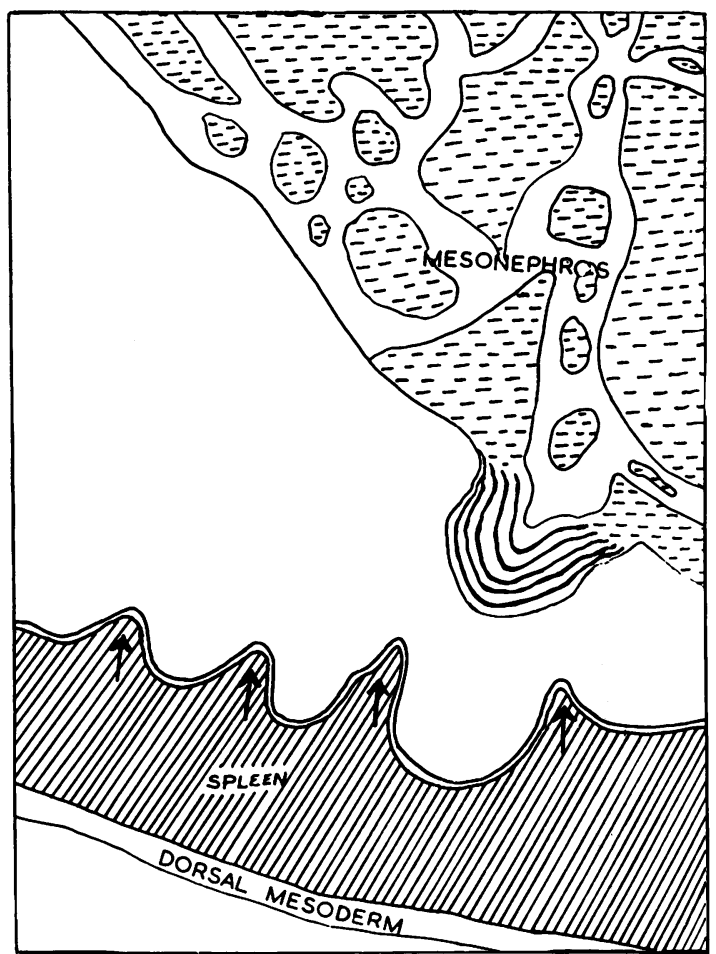

FIG. 6.-Diagram to show incorporation of mesonephric tissue into the hillocks to form inclusion cysts during the development of splenic primordium in dorsal mesogastrium.

The following simplified classification is believed to have practical advantages:

I. Non-parasitic cysts.

A. Primary or true cysts (Congenital).

1) Infoliation cysts.

2) Neoplastic cysts-

$$
\begin{aligned}
& \left.\begin{array}{l}
\text { Dermoid } \\
\text { Epidermoid }
\end{array}\right\} \\
& \begin{array}{r}
\text { Epithelial } \\
\text { lining. }
\end{array} \\
& \begin{array}{c}
\text { Lymphangioma } \\
\text { Endothelial } \\
\text { lining }
\end{array}
\end{aligned}
$$

B. Secondary or False cysts (Acquired).

1) Traumatic.

2) Inflammatory-Acute infection, malaria, tuberculosis.

3) Degenerative-Usually following infarction.

\section{Parasitic cysts.}

Echinococcus.

Primary cysts are characterised by some form of cellular lining. Infoliation cysts arise as a result of developmental defects during embryonic life. In the process of development of the spleen from the multiple hillocks which arise and project from the dorsal mesogastrium into the peritoneum, a part of the peritoneum 
may be pinched off, as a result of trauma or inflammation or due to rapid growth, and may form the nidus of a cyst (Fig. 6).

The origin of neoplastic cysts is still in doubt. Lubarsch (1927) assumes "a developmental disturbance, a faulty embryonal anlage". Secondary cysts account for about $60 \%$ of the total and result from trauma, inflammation or infarction. The only parasitic cyst of the spleen known is that of the echinococcus. In the present series the cysts were thought to be hæmangiomatous in one patient (Case 1), epidermoid in one (Case 4), and secondary in the other two (Cases $2 \& 3$ ).

\section{Summary}

Four cases of splenic cyst are described.

The difficulty of diagnosis is emphasised and it is suggested that percutaneous splenic venography may be valuable.

The pathogenesis of cysts of the spleen is briefly discussed and a new and simplified classification proposed.
I am gratefully indebted to Dr. A. Paton for his advice and help in preparing this paper. I wouted like to thank the Consultants, under whom the patients were treated, for permitting me to publis their cases. I would also like to thank Dr. A. E. Chaplin for producing the photomicrographs, Mir J. G. Williamson for the photographs, Dr. M. Zama who helped me in taking the clinical history of two patients, and Mrs. M. K. Mason for secretario assistance.

\section{REFERENCES}

Fowler, R. H. (1940): Cystic Tumours of the Spleem Int. Abstr. Surg., 70, 213. Int. Abstr. Surg., 70, 213 .
FowlER, R. H. (1953): Non-parasitic Cystic Tumours
of the Spleen. ibid, 96, 209 .

LUBARSCH, O. (1927): Die Cysten der Milz. Vol. $\vec{\psi}$ pp. 718-728. Im Handbuch der Spezdellen Path logischen Anatomie und Histologie. (Henke atg Lubarsch). Berlin: J. Springer.

MCClure, R. D. and ATtemeier, W. A. (1942) A Cyst of the Spleen. Ann. Surg., 116, 98.

SChechter, D. C., OWEnS, J. C., and Palmieri, A. 付 (1962): Hæmorrhagic Cyst of the Spleen. Amero J. Surg., 104, 777.

SMITH, R., and Gowing, N. F. C. (1953): Hæman̆ gioma of the Spleen. Relation to other Cyst Tumours. Case Report of Giant Cavernous Hæmangioma, Brit. J. Surg., 40, 566. 